\title{
Deformation of Scoria Cone by Conduit Pressurization
}

Edward S. Gaffney, Branko Damjanac, Donathon Krier, Greg Valentine

Abstract: A simplified mechanical model is used to simulate the deformation of a scoria cone due to pressurization of magma in a feeder conduit. The scoria cone is modelled as consisting of a cone of stabilized scoria with an axial region of loose scoria (height $h_{l}$ ), all overlying a vertically oriented cylindrical conduit intruded into rhyolite tuff country rock. For our analyses, the conduit is filled with basalt magma, usually with the upper length $\left(h_{2}\right)$ solidified. The style of deformation of the cone depends on both $h_{1}$ and $h_{2}$. If magma is prevented from hydrofracturing out of the conduit (as, for example, might be the case if the magma is surrounded by a solidified, but plastically deformable layer acting as a gasket backed up by the brittle country rock) pressures in the magma can build to $10 \mathrm{~s}^{\prime}$ of $\mathrm{MPa}$. When $h_{l}$ is $100 \mathrm{~m}$, not unusual for a small isolated basaltic cinder cone, the magma pressure needed to destabilize the cone when molten magma extends all the way to the original ground surface $\left(h_{2}=0\right)$ is only about one-third of the pressure when the upper part of the conduit is solidified $\left(h_{2}=25 \mathrm{~m}\right)$. In the former case, almost the entire upper third of the cone is at failure in tension when the configuration becomes unstable. In the latter case, small portions of the surface of the cone are failing in tension when instability occurs, but a large volume in the central core of the cone is failing in shear or compressions. These results may provide insight into the status of volcanic plumbing, either past or present, beneath scoria cones. Field observations at the Lathrop Wells volcano in southern Nevada identify structures at the outer edge just below the crater rim that appear to be inward-dipping listric normal faults. This may indicate that, near the end of its active stage, the cone was close to failing in this fashion. A companion paper suggests that such a failure could have been quite energetic had it occurred. 